Revista de

Contabilidade e

Organizações

www.rco.usp.br
DOI: http://dx.doi.org/10.11606/rco.v10i26.111202
Journal of

Accounting and

Organizations

www.rco.usp.br

\title{
O planejamento em municípios de pequeno porte em São Paulo
}

Ricardo Rocha de Azevedo ${ }^{a}$; André Carlos Busanelli de Aquino ${ }^{a}$

${ }^{a}$ Universidade de São Paulo

\section{Informações do Artigo}

Histórico do Artigo

Recebido: 23 de outubro de 2015

Aceito: 02 de maio de 2016

Palavras-chave:

Planejamento público.

Orçamento público.

Finanças públicas

Reforma orçamentária.

Municípios.

\begin{abstract}
Resumo
$\mathrm{O}$ presente artigo discute o planejamento em municípios de pequeno porte do estado de São Paulo. O estado atual do planejamento foi observado pela aplicação de questionário junto aos responsáveis pela elaboração do planejamento em uma amostra de 65 municípios de até 50mil habitantes. Os resultados mostram que nos municípios analisados o orçamento-programa (program-based budget), que seria um avanço na direção de obter uma melhor eficiência do gasto, ainda não é efetivo, e os programas e indicadores parecem ser mera peça formal. Em geral o orçamento é proposto de forma centralizada pelo contador, que faz o planejamento como uma rotina operacional (não estratégica), e com pouca participação das secretarias e dos demais órgãos da administração indireta. Tanto a participação popular quanto a legislativa no processo são baixas. Por outro lado, avanços começam a ser percebidos como o uso embrionário de medidas de desempenho.
\end{abstract}

Copyright (C) 2016 FEA-RP/USP. Todos os direitos reservados

\section{INTRODUÇÃO}

Mais de $89 \%$ dos municípios brasileiros possuem até 50 mil habitantes. O que poderia ser visto como uma vantagem pela proximidade dos governantes e vereadores ao cidadão pode ser negativamente balanceado pela carente estrutura administrativa refletida na qualidade do processo de planejamento.

Naturalmente, a administração local deve operar com estruturas administrativas mínimas para cumprir a gestão dos serviços locais. No Brasil, os municípios independentemente do porte, estão sujeitos às mesmas regras constitucionais e legais que determinam a elaboração de seu planejamento local, devendo estimar suas receitas e definir como os recursos serão aplicados, considerando ainda todas as regras fiscais estabelecidas pela Lei de Responsabilidade Fiscal (LRF). Tais atividades demandam equipes e sistemas de informação para operar processos em todo o ciclo de gestão financeira (Public Financial Management - PFM), que inclui o planejamento e orçamento, contabilidade e auditoria interna. Só operar tal ciclo já seria um desafio para municípios de pequeno porte, porém adicionalmente devem se adequar às novas condições impostas pelas reformas de PFM iniciadas nas últimas duas décadas.

Entre as reformas do ciclo de PFM, para mencionar apenas as principais pode-se citar: a criação do atual ciclo orçamentário de 4 anos e seus instrumentos: PPA (Plano Plurianual), LDO (Lei de Diretrizes Orçamentárias) e LOA (Lei Orçamentária Anual); a obrigatoriedade de definição de metas físicas para as ações e de indicadores para os programas; o estabelecimento de metas fiscais; maior transparência no processo orçamentário; controle por fontes de recursos, e ainda a definição pelos próprios entes dos programas e ações a serem executados.

Tais reformas seguem tendências internacionais, como a convergência contábil e adoção de princípios de outras visões de administração pública. No caso do processo de planejamento e orçamento, como destacado por Pollitt e Bouckaert (2011, p.82) não é tão evidente que a influência seja do que é conhecido hoje como New Public Management (NPM) ou de um modelo NWS (New-Weberian State). Independente da influência de escolas de pensamento, o ciclo de PFM em diversos países tem passado por constante reforma e é influenciado significativamente por padrões internacionais (ALLEN, 2009).

$\mathrm{O}$ alto índice de descentralização fiscal presente no Brasil, comparável com Estados Unidos, Canadá e

Autor Correspondente: Tel (16) 3315-0503

E-mail: ricardo.azevedo@usp.br (R. R. Azevedo); aaquino@usp.br (A. C. B. Aquino)

FEARP - USP - Avenida dos Bandeirantes n 3900 - Sala 5 - Bloco A - Monte Alegre - 14040900 - Ribeirão Preto, SP - Brasil 
países do norte europeu (GUESS; LELOUP, 2010, p. 202), somado à dificuldade de conduzir reformas de PFM para aprimorar a estrutura de administração local pode tornar ainda mais crítico o alerta de Rezende e Cunha (2013, p.17), que o orçamento público não tem cumprido sua função principal de servir como instrumento de controle da sociedade sobre os gastos públicos e como instrumento de discussão das prioridades dos entes, não apenas no Brasil, mas também países desenvolvidos como os Estados Unidos (JOYCE, 2012).

Motivado pela realidade da fragmentação de municípios no Brasil, e pela representatividade dos municípios de pequeno porte com as potenciais restrições de recursos para conduzirem a administração local, o presente artigo questiona se tais municípios estariam conseguindo assimilar as constantes reformas no ciclo de PFM que os entes da federação estão sujeitos. Com especial atenção ao processo de planejamento, são discutidas as dificuldades estruturais, como baixo orçamento e escassez de recursos humanos e financeiros para implementar as mudanças. Para tanto foi aplicado um questionário a servidores públicos responsáveis diretos pelo processo de elaboração do planejamento de municípios de até 50 mil habitantes no Estado de São Paulo. As respostas válidas enviadas por 65 municípios foram cruzadas com informações do plano vigente de cada município enviado ao Tribunal de Contas de São Paulo.

A seguir são apresentados os aspectos estruturantes do planejamento municipal no Brasil, assim como a proposição das fases do planejamento na regulação do PFM de municípios. Segue-se com a discussão das dificuldades estruturais dos municípios de pequeno porte, e a descrição do método e da amostra utilizados. Por fim discutem-se os resultados e são apresentadas as considerações finais.

\section{O PLANEJAMENTO MUNICIPAL NO BRASIL}

A discussão de planejamento no setor público surgiu da busca de aperfeiçoamento dos modelos de orçamento adotados. Em 1949 a comissão Hoover nos Estados Unidos propôs a substituição do modelo baseado em recursos, no qual a avaliação se resume ao cumprimento da alocação prevista (input-based budgeting) para um modelo de orçamento em que a avaliação se daria pelos resultados gerados pelos recursos alocados (output-based budgeting, result-based budgeting ou performance-based budgeting) (MCGILL, 2001). Em 1965, outra reforma no orçamento daquele país propôs o orçamento-programa (planning-programming budgeting-system - PPBS), e finalmente a gestão por objetivos (management by objectives - MBO) em 1973. No orçamento-programa o programa - é a unidade central da análise de planejamento, alocação de recursos e análise de desempenho, que pode ser quantificado e analisado para melhor decisão no processo orçamentário. O PPBS estrutura melhor o plano, mas não associa o plano com a estrutura administrativa que irá implantá-lo. A gestão por objetivos faz o alinhamento do plano com servidores seniores, que serão responsabilizados pelos objetivos e metas dos programas que consomem recursos no orçamento (MCGILL, 2001).

A mudança para o orçamento por resultados é lenta e gradual, como apontam Pollitt e Bouckaert (2011, p.80). Em meados dos anos 90, quando o Brasil estava imerso na implantação do Plano Real, Flynn (1995) descreveu as principais mudanças no processo orçamentário em países desenvolvidos, especialmente no foco em medir resultados em busca de análise de eficiência e o uso de planejamento multi-período (plurianual). O autor destacou esforços de mudanças, como o uso de metas e objetivos na França e Suécia (até então sem sucesso) e Áustria (antes meramente um cumprimento legal), e a imposição (top-down) de objetivos na Suíça e Suécia. Contudo nesses casos citados, o orçamento era baseado apenas nos recursos consumidos (input-based budgeting).

No plano municipal muitas transformações estavam ocorrendo, com a chamada "municipalização das receitas" decorrente da descentralização fiscal da Constituição de 1988. Pode-se dizer que os municípios brasileiros operam no mesmo modelo de PFM há pouco mais de uma década, pois só a partir de então o modelo vigente no Brasil de orçamento-programa ${ }^{1}$ começou a se descolar do orçamento por linha (line item budgeting) da lei 4.320/64, que perdurou até 2002, quando entrou em vigor a Portaria MOG 42/99. Ela determinou aos entes da federação criar seus próprios programas governamentais, incluindo o nome de cada programa, os objetivos, público alvo e as suas metas ou indicadores.

\subsection{Fases do planejamento no ciclo PFM em municípios brasileiros}


por desempenho e o controle, auxiliando na restrição do aumento dos gastos e no ganho de eficiência e efetividade no uso dos recursos públicos (POLLITT; BOUCKAERT, 2011, p.77). Para tanto, o orçamento-programa vai além da simples alocação de receitas e despesas, e se torna um instrumento de planejamento que associa ações e recursos empregados (input) aos resultados gerados (outputs) e aos impactos desses na sociedade (outcome) (BISSESSAR, 2010; MACHADO Jr., 2012)postlu20101960s and 1990s to present New Public Management (NPM budgeting, uma verdadeira "reinvenção do orçamento público" (REZENDE; CUNHA, 2013, p.248). No Brasil esta transformação pode ser vista dividida em 4 fases, segundo os marcos regulatórios, sendo que a quarta fase ainda está em implantação. As fases são as seguintes: (i) orçamentária tradicional; (ii) pós-constitucional; (iii) transição e (iv) orçamento-programa (Figura 1).

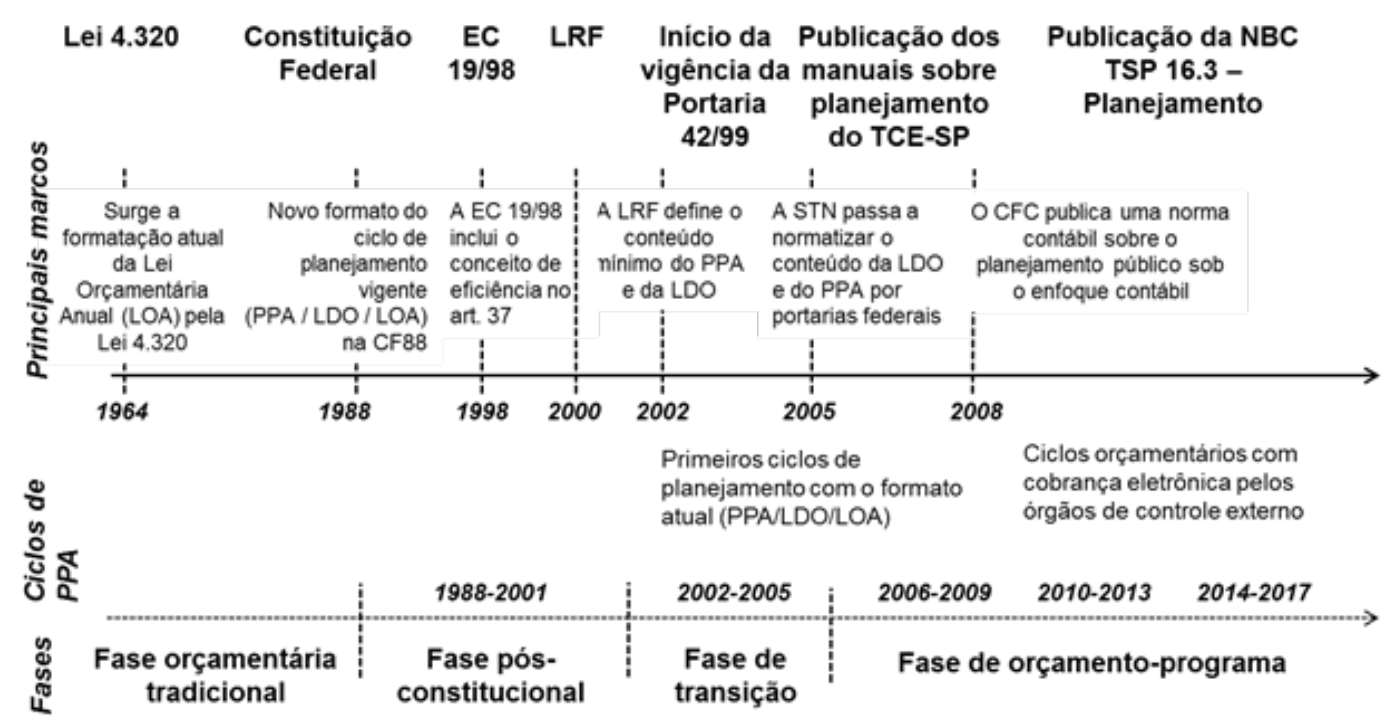

Figura 1. Evolução dos ciclos operacionais

Fonte: elaborado pelos autores

Até poucas décadas atrás, o orçamento público era simples e sintético, entendido como um instrumento técnico da contabilidade para registro e análise dos gastos. Não incluía a geração de um "plano de trabalho", e continha apenas o emprego de recursos segundo classificações que permitissem sua avaliação pelas Câmaras Legislativas (MACHADO JR., 2012). Apenas em 1956 o orçamento passou a ser detalhado em unidades administrativas, permitindo ao Legislativo a análise dos gastos por setor, quando passou a segregar as “despesas ordinárias (custeio e transferência) das de capital" (ROCQUE, 1963, p.147). Diversas regulamentações transformaram os modelos anteriores no modelo da Lei 4320, que também incluía uma estrutura de classificação das receitas e despesas para elaboração do orçamento. Exceto a experimentação pelo governo federal de alguns planos quinquenais, o modelo seguiu sem grandes avanços até o final da década de 80 (LOPES, 1990).

A primeira fase (fase orçamentária tradicional), da edição da Lei 4320/64 à promulgação da Constituição Federal de 1988, é marcada pelo modelo conhecido como orçamento por linha (line item budgeting). O planejamento com foco nos resultados não era institucionalizado, e se ocorresse seria uma iniciativa isolada e específica para grandes projetos. $\mathrm{O}$ orçamento se resumia à previsão de receitas e decisão de alocação de recursos em secretarias e funções de governo para o exercício seguinte. A denominação "programas de governo" apesar de já ser utilizada desde a lei 4.320/64, não deve ser tomada como sendo o conceito internacional de orçamentoprograma (program-based budgeting), pois o conceito de programa empregado era nada mais que uma classificação contábil padronizada para gastos na federação, previamente definida no anexo da própria Lei 4320.

Pode-se dizer que antes do modelo PPA-LDO-LOA criado pela Constituição Federal de 1988 o planejamento praticamente inexistia no setor público brasileiro. O que mais se aproximaria era o Orçamento Plurianual de Investimentos (OPI) para 3 anos, prevendo dotações como despesa de capital (contudo sem a definição de metas).

A segunda fase (fase pós-constitucional) é marcada pelas mudanças no ciclo do planejamento promovidas pela Constituição, que previu o planejamento plurianual associado às metas (PPA), e os desdobramentos em leis anuais (LDO e LOA). Este seria o início do orçamento-programa, contudo, a lista de programas ainda era fornecida (top-down). Assim, o orçamento dos entes não refletia seus reais programas, mas sim uma lista padronizada de funções, o que fez com que o orçamento ainda se mantivesse como um orçamento por linha. Tal 
modelo permaneceu genérico e sem a cobrança de resultados físicos, visando apenas o atendimento aos limites constitucionais de educação (em 1988) e saúde (em 2000). Nessa fase os softwares dos municípios não estavam adequados às mudanças, e havia baixa cobrança pelos controles externos, com pouca orientação sobre como fazer o novo modelo de planejamento. No ano de 1999, o Perfil dos Municípios Brasileiros publicado pelo IBGE apontava que cerca de 250 municípios brasileiros ainda não tinham iniciado a edição da LDO anual, e outros 750 municípios ainda não possuíam o plano de 4 anos (PPA).

Muitos municípios não adotaram inicialmente os novos instrumentos, seja pela falta de recursos internos, seja pela falta da legislação disciplinadora (conforme dispõe o art. $165, \S 9^{\circ}$ da Constituição Federal), o que levou inicialmente muitos municípios a deixarem de atender à elaboração dos instrumentos de planejamento, alguns inclusive apoiados em entendimentos de órgãos de Controle Externo (GIACOMONI, 2004).

Foi apenas no ano 2000 com a publicação da LRF que os instrumentos PPA-LDO-LOA começaram a ser compreendidos e implantados. A LRF trouxe capítulos específicos para o planejamento público e definiu o conteúdo mínimo que a LDO deveria possuir, diminuindo as incertezas sobre a metodologia. A LRF também passou a exigir dos entes a fixação de metas físicas para as ações governamentais, além das metas financeiras, assim como a apresentação das mesmas em audiências periódicas à sociedade. Criou também mecanismos de controle fiscal no planejamento, como o estabelecimento de riscos fiscais e fixação de metas fiscais (resultado nominal, primário, e meta máxima de endividamento total). Contudo, a lista de programas padronizada continuava a ser fornecida pelo governo federal (top-down) e as políticas dos governos locais não estavam refletidas nos programas genéricos de seus orçamentos. Merece destaque que a Emenda Constitucional 19 de 1998 incluiu nas obrigações do gestor público a dimensão de "eficiência", preparando as bases para ampliação do orçamento por programa com metas físicas, para um futuro orçamento por resultados (output-based budegting) com foco na eficiência dos recursos.

A terceira fase (fase de transição) marca o início do orçamento-programa no Brasil. A partir de 2002 (Portaria MPOG 42/99) os programas passaram a ser elaborados pelos entes, que estruturavam agora seus próprios programas, com seus objetivos e indicadores segundo suas políticas públicas locais. Os municípios adicionalmente passaram a planejar sua política urbana no Plano Diretor (Lei Federal 10.257/2001), que deveria conter regras gerais de utilização do solo, urbanização das áreas do município, servindo como base para a elaboração do PPA como previsto na própria lei. A implantação deste novo instrumento não foi imediata, em 2005 apenas 14,5\% dos municípios que estavam obrigados possuíam seu plano aprovado no legislativo local (IBGE, 1999).

Este período foi marcado pelo $1^{\circ}$ plano plurianual no conceito de orçamento-programa, assim os municípios estavam ainda experimentando o novo modelo. Os softwares de planejamento dos municípios foram atualizados para suportar os novos processos de planejamento, incluindo novas rotinas, bases de dados e relatórios. Deveriam permitir estruturação por programas, detalhamento das ações, e fixação de metas físicas para cada ação, associado com os recursos a serem alocados no orçamento, para posterior avaliação. Também nesse período alguns Tribunais de Contas passam a demandar o envio eletrônico do planejamento vigente.

Por fim, na quarta fase (fase de orçamento-programa) a partir de 2006, depois da primeira tentativa de PPA, e passada a elaboração do Plano Diretor, os municípios passaram por mais 3 ciclos de PPAs. Esta fase é marcada pelo aprimoramento dos Tribunais de Contas a partir do Programa de Modernização do Controle Externo (Promoex), que lhes trouxe maior modernização tecnológica (LOUREIRO; TEIXEIRA; MORAES, 2009) e pelo início do processo de convergência da contabilidade pública a padrões internacionais, que levou à adoção de um plano de contas padronizado e consequente readequação de sistemas de informação.

Nesse período os municípios passaram a elaborar e divulgar metas físicas e indicadores de seus programas, como passou a ser recomendado pelo TCE-SP no "Manual de elaboração do planejamento" (respectivamente sobre PPA, LDO e LOA), publicado em 2005, que operacionalizou as regras da legislação para o próximo PPA dos municípios, de 2006 em diante, que passaram a contar com metas físicas, além das demais regras do novo planejamento.

Nessa fase começou efetivamente a cobrança automatizada do planejamento pelo controle externo em alguns estados. Também começou a adoção de indicadores para os programas de governo e a utilização de metas físicas para as ações. Parte do programa de modernização das cortes de contas, iniciado em 2006 entre a Associação dos membros dos Tribunais de Contas (ATRICON) e Banco Mundial, o Tribunal de Contas de São Paulo lançou em 2008 a informatização da coleta dos dados dos órgãos jurisdicionados. A partir de então o acompanhamento passou a ser feito eletronicamente, com menor custo e de forma mais eficiente, pois ações, programas, receitas previstas e arrecadadas e as despesas fixadas e executadas são avaliadas por regras de sistema nos softwares, que em caso de descumprimento dispara a emissão de alertas automáticos que são publicados no próprio site do Tribunal. Por sua vez, os softwares de planejamento dos municípios foram atualizados para a geração das novas 
informações (AQUINO; AZEVEDO; LINO, 2016).

\subsection{Resistências à adoção das reformas de PFM em municípios de pequeno porte}

Estudos de implantação de reformas de PFM em diversos países têm mostrado que a mudança da regulação (leis, decretos, portarias) é parte necessária, mas não suficiente para concluir a reforma (ANDREWS, 2013). Acadêmicos, consultores e agências multilaterais concordam que fatores de resistência podem impedir que as leis (dimensão regulatória) sejam transformadas e aceitas por diversos atores (dimensão normativa), e incorporadas por eles em suas práticas (dimensão cultural-cognitiva) (ANDREWS, 2013; SCOTT, 2014).

Como trata a literatura de difusão de reformas, municípios enquanto governos locais irão responder à mesma reforma orientada pelo governo central segundo a resistência de sua própria burocracia e representação política, e segundo os recursos que contam para implantar as reformas (MOON; DELEON, 2000). No caso de municípios de pequeno porte a restrição de recursos seria fator restritivo, mesmo que outras fontes de resistência fossem vencidas.

Como mencionado anteriormente, as reformas foram sendo feitas na regulação do PFM, sobretudo a partir de 1988, com forte impacto da LRF a partir de 2000. Como a flexibilização pelo porte do município ao atendimento da regulação do PFM no Brasil é mínima, o impacto para municípios de pequeno porte pode ser desproporcional. Exceto a maior periodicidade para divulgação de demonstrativos fiscais (semestralmente, dada pela LRF) ou o maior prazo de implantação de transparência (LC 131/2009), municípios de pequeno porte são obrigados a seguir as mesmas regras e prazos tanto na sua elaboração do planejamento quanto no envio de dados aos Ministérios e aos Tribunais.

$\mathrm{O}$ porte e a consequente restrição de recursos poderiam afetar 3 elementos relevantes à implantação das reformas de PFM: (i) a estrutura administrativa do executivo local, (ii) o controle interno, (iii) o controle legislativo. Enquanto a estrutura administrativa opera o ciclo PFM (planejamento, orçamento, contabilidade e auditoria), avalia a execução do ciclo pela prefeitura e demais entidades municipais e induz melhorias no próprio ciclo, o controle legislativo aumentaria o escrutínio nos planos e resultados gerados, também induzindo melhorias no ciclo. Se o controle interno e o legislativo são distantes ou ausentes à execução do ciclo de PFM, este tende a ser nivelado pelos escassos recursos disponíveis e interesses de curto prazo. A combinação de carências nesses elementos inibe reformas de PFM em governos locais, mesmo que fatores institucionais (normativos e culturalcognitivos) sejam favoráveis.

A função de arrecadação, uma das primeiras a serem aprimoradas no contexto da descentralização fiscal, pode mostrar a carência da administração local. A questão da arrecadação pode ser vista na desatualização de cadastros mobiliários e na inexistência de plantas genéricas de valor. Destaca-se da Tabela 1 apesar da cobrança do IPTU já ter alcançado $93 \%$ dos municípios, $28 \%$ ainda não possuíam uma planta genérica de valor que serviria de base para o imposto. Ainda, outras taxas são menos comuns e a existência de cadastro de ISS ainda não está presente em $16 \%$ dos municípios.

Tabela 1. Estrutura de arrecadação dos municípios em 2009

\begin{tabular}{lcc}
\hline Estrutura de Arrecadação & Possui & N \\
\hline O município cobra IPTU & $93 \%$ & 5.565 \\
O município cobra taxa de: Iluminação pública & $70 \%$ & 5.565 \\
O município cobra taxa de: Coleta de lixo & $49 \%$ & 5.565 \\
O município cobra taxa de: Limpeza pública & $43 \%$ & 5.565 \\
Cadastro imobiliário - existência & $94 \%$ & 5.565 \\
Cadastro imobiliário informatizado - existência & $89 \%$ & 5.206 \\
Planta Genérica de Valores - existência & $72 \%$ & 5.565 \\
Planta Genérica de Valores informatizada - existência & $78 \%$ & 4.020 \\
Cadastro ISS - existência & $84 \%$ & 5.565 \\
Cadastro ISS informatizado - existência & $81 \%$ & 4.664 \\
\hline
\end{tabular}

Fonte: Elaborado a partir de dados do Perfil de Municípios do IBGE para ano de 2009 
Em 2001, Mello (2001) já apontava para a carência de capacidade técnica no corpo de funcionários municipais, incluindo contadores, dificultando a própria elaboração do relatório anual de prestação de contas, a ser enviado à Câmara Municipal. Se hoje tal função pode ter sido melhor estruturada dada a coerção dos Tribunais de Contas, o mesmo não pode ser esperado em relação à função de planejamento. Municípios sem uma estrutura mínima de arrecadação e que dependem exclusivamente de transferências de outras esferas de governo possuem ciclos de PFM menos complexos (ex. a estimação de receitas é o crescimento orçamentário vinculado ao estado e à União), possuem menos recursos humanos e financeiros para implementar reformas, e são menos propensos a se sensibilizarem (reconhecerem e aceitarem) pelas melhorias propostas pelas reformas.

A falta de recursos pode também ser observada nos gastos nas subfunções planejamento e orçamento e controle interno, onde respectivamente apenas 1.422 e 1.700 municípios registraram gastos nestas subfunções (Tabela 2). Isso pode indicar que a elaboração do PPA e seus desdobramentos nas estimativas para LDO e LOA, além do monitoramento do orçamento, são executados em tempo parcial por servidores da Secretaria de Finanças.

Tabela 2. Gastos em planejamento e controle interno (2013)

\begin{tabular}{lccccc}
\hline \multicolumn{1}{c}{ Região } & N & \multicolumn{2}{c}{ Gastos segregados em } & \multicolumn{2}{c}{ Gastos segregados em } \\
& & planejamento $>\mathbf{0}$ & \multicolumn{2}{c}{ controle interno $>\mathbf{0}$} \\
& & $\mathbf{N}$ & $\mathbf{\%}$ & $\mathbf{N}$ & $\mathbf{\%}$ \\
\hline Centro Oeste & 471 & 99 & $21 \%$ & 109 & $23 \%$ \\
Norte & 446 & 104 & $23 \%$ & 125 & $28 \%$ \\
Nordeste & 1.794 & 360 & $20 \%$ & 558 & $31 \%$ \\
Sul & 1.191 & 405 & $34 \%$ & 364 & $31 \%$ \\
Sudeste & 1.668 & 454 & $27 \%$ & 544 & $33 \%$ \\
Total & 5.570 & 1.422 & $26 \%$ & 1.700 & $31 \%$ \\
\hline
\end{tabular}

Fonte: Elaborado a partir de dados FINBRA (STN) para o ano de 2013

Equipes reduzidas ou mesmo ausência de Controle Interno nos municípios deixa a cargo dos Tribunais de Contas todo esforço de fiscalização do cumprimento do ciclo de PFM pelo município.

Em relação ao controle legislativo, o escrutínio nos planos e resultados gerados dependeria da atuação do legislativo e do Tribunal de Contas. Enquanto as esferas federal e estadual possuem uma estrutura legislativa mais robusta ${ }^{2}$, mesmo os municípios de maior porte não contam com tal estrutura. Em municípios de até 50 mil habitantes, um menor número de vereadores (varia de 9 a 13) pode significar menor capacidade de escrutínio e comitês de orçamento e finanças menos operantes.

O suporte ao controle legislativo dado pelos Tribunais de Contas poderia ser positivamente afetado por um menor porte do ente, por possibilitar uma fiscalização mais pormenorizada. Porém, a coerção do Tribunal viria da periodicidade de auditorias in loco, do conhecimento prévio da visita e do rodízio de auditores, da automatização da coleta de dados e procedimentos técnicos adotados e, como tratado em Arantes et al (2005), do equilíbrio de critérios técnico-políticos empregados pelos conselheiros em cada Tribunal. Adicionalmente, fatores como distância até a capital do estado, dispersão geográfica e dificuldade de acesso ao município poderiam afetar a atuação das cortes de contas, assim como tornar o pequeno município mais alheio às reformas.

\section{DADOS E AMOSTRA}

Como amostra para levantar a realidade dos municípios de pequeno porte foi aplicado um questionário direcionado aos servidores responsáveis diretos pelo processo de planejamento em municípios com população inferior a 50 mil habitantes do Estado de São Paulo. Em 2014 esta faixa representava mais de 80\% dos municípios paulistas.

O questionário foi divulgado em redes profissionais de gestores envolvidos com o planejamento público, 
e deixado disponível para resposta online por 3 meses.

O questionário de 46 questões fechadas (25 delas são utilizadas na presente análise) utilizando escala likert quando tratou da percepção do respondente cobriu os seguintes blocos: (a) organização interna da estrutura de planejamento; (b) participação legislativa e popular na elaboração do planejamento; (c) nível de maturidade na mensuração do orçamento; (d) metodologia de elaboração do orçamento. Foi realizado pré-teste com dois consultores da área contábil municipal, além de dois servidores responsáveis pelo planejamento em seus municípios. Após eliminação de respostas incompletas ou inválidas ${ }^{3}$, foram obtidas 65 respostas válidas.

A Tabela 3 apresenta a distribuição das respostas válidas em relação à composição populacional do Brasil e do Estado de São Paulo. No Brasil são 4.956 municípios com população menor de 50 mil habitantes, sendo que $51 \%$ com população menor de 10 mil, em São Paulo 278 casos (54\%). Com pequenas variações, a amostra está equilibrada nas três faixas tratadas.

Para estes municípios foram coletadas no Portal do Cidadão mantido pelo Tribunal de Contas de São Paulo informações dos programas, indicadores, ações de governo e respectivas metas de cada ação, enviados anualmente ao Tribunal.

Tabela 3. Características dos municípios da amostra

\begin{tabular}{cccccccc}
\hline $\begin{array}{c}\text { População } \\
\text { (mil hab.) }\end{array}$ & $\begin{array}{c}\text { Municípios do } \\
\text { País }\end{array}$ & \multicolumn{4}{c}{$\begin{array}{c}\text { Municípios do } \\
\text { Estado de SP }\end{array}$} & $\begin{array}{c}\text { Municípios } \\
\text { da amostra }\end{array}$ & $\begin{array}{c}\text { \% } \\
\text { amostra }\end{array}$ \\
& $\mathrm{n}$ & $\%$ & $\mathrm{n}$ & $\%$ & $\mathrm{n}$ & $\%$ & \\
\hline$\leq 10$ & 2.514 & 51 & 278 & 54 & 29 & 45 & 10 \\
de 10 a 25 & 1.742 & 35 & 152 & 29 & 21 & 32 & 14 \\
de 25 a 50 & 700 & 14 & 88 & 17 & 15 & 23 & 17 \\
Total $\leq 50$ & 4.956 & 100 & 518 & 100 & 65 & 100 & \\
$>50$ & 612 & & 127 & & 0 & & \\
Total & 5.568 & 645 & & 65 & \\
\hline $\begin{array}{l}\text { Nota. A porcentagem da amostra é a relação percentual entre o número de municípios } \\
\text { da amostra em comparação com os municípios do Estado de São Paulo, por faixa } \\
\text { populacional. }\end{array}$ \\
Fonte: dados da pesquisa \\
\hline
\end{tabular}

A amostra de 65 municípios é formada por municípios jovens (71 anos de idade em média). O tamanho do orçamento de alguns municípios pode ajudar a explicar a dificuldade de manter uma equipe de planejamento com dedicação exclusiva à essa atividade, dado que tais recursos para estes fins viriam das receitas próprias com pouco ou nenhum do governo federal ou estadual (Tabela 4).

Tabela 4. Características gerais dos municípios da amostra

\begin{tabular}{ccccccccc}
\hline & \multicolumn{3}{c}{ Amostra $(\mathbf{n = 6 5})$} & \multicolumn{4}{c}{$\begin{array}{c}\text { Municípios paulistas abaixo } \\
\text { de 50.000 habitantes (n=515) }\end{array}$} \\
\hline & média & desv .pad & mín. & máx. & média & desv. pad & mín. & máx. \\
População (mil hab.) & 16 & 12 & 1,7 & 43 & 14 & 12 & 0.8 & 50 \\
Distância da Capital (km) & 409 & 167 & 60 & 800 & 383 & 171 & 31 & 800 \\
PIB per capita. (R\$ mil) & 17.2 & 11 & 7 & 90.5 & 19.6 & 18.2 & 6.3 & 241 \\
Orçamento per capita & 2.568 & 885 & 1.379 & 5.407 & 3.541 & 12.112 & 755 & 9.900 \\
Área (km²) & 416 & 277 & 63 & 1.253 & 363 & 296 & 5 & 1.977 \\
Idade (anos) & 71 & 28 & 15 & 138 & 76 & 52 & 15 & 451 \\
Índice IEGM / TCE-SP (2015) & 3,2 & 1,2 & 1 & 5 & 3,3 & 1,2 & 1 & 5 \\
\hline
\end{tabular}

Fonte: Construído a partir de dados do SIAPNET - Tribunal de Contas do Estado de São Paulo. 
A amostra possui um PIB médio de R $\$ 17,2$ mil per capita, inferior ao PIB médio dos municípios com menos de 50mil habitantes. O PIB menor poderia suscitar que a amostra não representaria os 515 casos do estrato com menos de 50mil habitantes. Contudo, o Índice de Efetividade da Gestão Municipal (IEGM) divulgado pelo TCE-SP para o ano de 2015, mostra que os 65 casos da amostra em média têm uma gestão qualificada em 3.2 (escala de 1 a 5), enquanto os 515 municípios no estado uma média de 3,3. Portanto, uma menor PIB não guarda associação com capacidade de gestão.

\section{RESULTADOS}

Dada a mudança de regulação comentada, os municípios estariam em algum grau de assimilação do conteúdo das reformas do orçamento-programa desde 2002. O grau de implantação do conteúdo central da reforma de orçamento-programa pode ser observado em duas etapas: (i) estruturação do plano em programa, pela associação dos recursos nos diversos programas definidos segundo políticas públicas locais, desenhadas a partir do PPA, à indicadores e metas e (ii) uso da informação para avaliação do desempenho dos programas, indo além da avaliação fiscal da execução orçamentária.

A Tabela 5 apresenta a percepção dos responsáveis pelo processo de planejamento dos 65 municípios em relação ao uso dos instrumentos na administração local. Apesar deles próprios considerarem o PPA como um importante instrumento (4.3), não estão seguros (3.1) em afirmar que os indicadores e metas físicas são utilizados gerencialmente, ou seja, para avaliar a execução do planejamento. Ainda, consideram que o gestor não dá atenção devida ao planejamento quando está elaborando os instrumentos, assim como não os usa para gestão (4.1). Essa baixa atenção aos instrumentos é ainda confirmada por não considerarem a adoção de um planejamento de longo prazo, como para 20 anos (2.2).

Apesar da baixa atenção ao uso, a elaboração dos instrumentos segue o rito esperado. A LOA é elaborada baseada no PPA revisto e as regras previstas na LDO são respeitadas na LOA (4.2).

Tabela 5. Percepção sobre o uso dos instrumentos de orçamento-programa

\begin{tabular}{lcc}
\hline Questões & Média & $\begin{array}{c}\text { Desvio } \\
\text { Padrão }\end{array}$ \\
\hline O Plano Plurianual é uma importante ferramenta estratégica para as entidades ${ }^{(2)}$ & 4,3 & 1,1 \\
$\begin{array}{l}\text { As informações sobre os indicadores dos programas e as metas físicas das ações } \\
\text { são utilizadas gerencialmente por parte das entidades }{ }^{(2)}\end{array}$ & 3,1 & 1,4 \\
O gestor não dá a devida atenção (ao planejamento público) quando elabora o & 4,1 & 1,1 \\
PPA-LDO-LOA e não os utiliza para gestão ${ }^{(2)}$ & 2,2 & 1,4 \\
O município já discute a elaboração de um planejamento de no mínimo 20 anos ${ }^{(2)}$ & 2,5 \\
$\begin{array}{l}\text { A LOA, em geral, é gerada diretamente a partir dos dados do PPA original, sem } \\
\text { preocupação a revisão anual do PPA.(2) }\end{array}$ & 2,5 \\
$\begin{array}{l}\text { As regras implementadas pela LDO são respeitadas na elaboração da LOA.(2) } \\
\text { Orçamento inclui metas físicas nas ações }{ }^{(1)}\end{array}$ & 4,2 & 1,0 \\
Orçamento inclui indicadores nos programas ${ }^{(1)}$ & 0,93 & 0,249 \\
\hline
\end{tabular}

Obs. (1) Escala adotada para essas questões: (0 - não adota, 1 - adota); (2) Para essas questões adotou-se a escala likert: (1-discordo totalmente; 3 -indiferente; 5 -concordo plenamente).

Fonte: Dados da pesquisa

Ao serem questionados se seus orçamentos possuíam metas físicas para as ações e indicadores para programas, a maior parte respondeu positivamente $(0,93$ e 0,89$)$. Como municípios paulistas devem transmitir eletronicamente o planejamento ao Tribunal (Projeto AUDESP), este alto percentual é esperado, pois devem legitimar sua prestação de contas. Porém, a existência dos programas, indicadores e metas não deve ser vista como 
uso efetivo, sobretudo pela percepção dos responsáveis de que os indicadores não são usados para gestão.

A Tabela 6 apresenta a transmissão de indicadores dos programas e metas das ações para o TCE-SP no ano de 2013. Cinco anos após o início da informatização dessa prestação de contas pelo TCE-SP, para municípios com menos de 50 mil habitantes, em média 34\% das ações foram transmitidas com meta zerada ou meta não informada. Para os municípios da amostra, cada programa de governo em média contava com 2,5 indicadores de desempenho. Das 92 ações em média, 44 são finalísticas (saúde, educação e assistência social) e 48 são não finalísticas. Das 44 ações finalísticas, $28 \%$ delas não possuíam metas informadas. Interessante notar que a natureza da ação (finalística ou não finalística) não afeta a propensão a adotar metas ou a ausência de metas não informadas. Comportamento muito similar aos demais municípios de pequeno porte ( $\leq 50$ mil habitantes) do estado.

Tabela 6. Previsão de metas por ação e indicadores por programas

\begin{tabular}{|c|c|c|c|c|c|c|}
\hline \multirow{2}{*}{$\begin{array}{l}\text { Municípios por porte } \\
\text { (mil habitantes) }\end{array}$} & \multicolumn{2}{|c|}{$\begin{array}{c}\text { Ações governamentais por } \\
\text { município }\end{array}$} & \multicolumn{2}{|c|}{$\begin{array}{l}\text { \% de ações com metas } \\
\text { zeradas ou não informadas }\end{array}$} & \multirow{2}{*}{$\begin{array}{c}\text { Programas } \\
\text { por } \\
\text { município } \\
\text { (Média) }\end{array}$} & \multirow{2}{*}{$\begin{array}{c}\text { Indicadores } \\
\text { por } \\
\text { programa } \\
\text { (Média) }\end{array}$} \\
\hline & Finalísticas & Não finalísticas & Finalísticas & Não finalísticas & & \\
\hline$\leq 50$ & $46,4(29,3)$ & $48,9(36,4)$ & $27,6(34,2)$ & $27,4(34,3)$ & $28,3(16,5)$ & $2,1(1,8)$ \\
\hline de 50 a 100 & $92,8(58,3)$ & $114,4(71,1)$ & $33,2(33,5)$ & $29,1(33)$ & $44,8(31)$ & $2,1(1,6)$ \\
\hline de 100 e 500 & $175,3(132,2)$ & $252,9(234,3)$ & $39,4(34,6)$ & $36,7(34,6)$ & $54,7(48,1)$ & $2,4(3)$ \\
\hline Acima de 500 & $323,4(398,8)$ & $459,3(455,5)$ & $25,8(30,2)$ & $27,7(29,5)$ & $57,2(13,3)$ & $3,2(3)$ \\
\hline Municípios da amostra & $44,8(26,3)$ & $47,5(28,4)$ & $27,6(36,8)$ & $26,5(37)$ & $25,3(15,2)$ & $2,5(2,6)$ \\
\hline
\end{tabular}

Fonte: elaborado a partir dos dados do Portal do Cidadão - TCE-SP

Notas: 1. Os dados apresentados são apenas das prefeituras, e não incluem indicadores das Câmaras municipais e das autarquias. 2. Os números representam a média, e os números entre parênteses o desvio padrão

Pode-se dizer que, talvez pela atuação do Tribunal de Contas, a primeira parte do conteúdo central da reforma de orçamento-programa está sendo implantada, e os planos dos municípios estão se estruturando em programas. Porém, a segunda etapa, onde os municípios passariam a utilizar essa informação para avaliação do desempenho dos programas ainda está longe de ocorrer.

A dinâmica orçamentária pode ainda estar exclusivamente sendo pautada pela alocação dos recursos (input-based), e não pelos outputs como desejado pelo modelo do orçamento-programa. Se observa ainda a tendência ao método incremental (Tabela 7), sobretudo para as despesas, que é o método que projeta o período futuro a partir dos valores executados no período anterior.

O uso de método incremental para a receita é menos recorrente $(0,66)$ do que para as despesas com pessoal $(0,97)$. Diferente da previsibilidade das despesas de pessoal e encargos que anualmente sofrem poucas mudanças pela estabilidade do quadro de servidores, a previsão das demais despesas correntes deveria estar mais associada às ações a serem executadas e de uma avaliação dos resultados obtidos no atual período, do que serem a mera projeção dos períodos anteriores, o que pode mostrar uma tendência em perpetuar o nível de gasto das unidades (SCHICK, 1983). Nesta condição, os secretários não possuem incentivos para a economia de despesas, dado que uma economia levaria à diminuição de seu orçamento no próximo exercício.

Tabela 7. Estimação do orçamento

\begin{tabular}{|c|c|c|}
\hline Questões & Média & Desvio Padrão \\
\hline Estimação incremental $^{(1)}$ para receitas & 0,66 & 0,476 \\
\hline Estimação incremental ${ }^{(1)}$ para despesas de pessoal e encargos & 0,97 & 0,175 \\
\hline Estimação incremental ${ }^{(1)}$ para outras despesas correntes & 0,94 & 0,242 \\
\hline $\begin{array}{l}\text { O excesso de arrecadação é recorrente, a estimação da receita é subdimensionada (a } \\
\text { receita é prevista a menor do que a capacidade real de arrecadação) }\end{array}$ & 4.10 & 1.30 \\
\hline
\end{tabular}

Obs. (1) Estimação ancorada em exercícios anteriores (incremental): 0 - não adota; 1-adota; (2) Escala likert: 1-discordo totalmente; 3 - indiferente, 5-concordo plenamente.

Fonte: Dados da pesquisa 
A confirmação de que o excesso de arrecadação é recorrente (4.1), e que seria decorrente da subestimação da receita, abre espaço para considerar que a subestimação da receita é adotada para permitir espaços de manobra para o prefeito atuar na alocação de créditos suplementares no ex-post. Estas manobras podem ser usadas para compensar incertezas decorrentes de um processo de planejamento impreciso ou para reduzir o controle legislativo sobre o orçamento inicial, em ambos os casos atesta um cenário de accountability prejudicial ao desenvolvimento do orçamento-programa.

Tabela 8. Análise da organização interna da estrutura de planejamento

\begin{tabular}{lcc}
\hline Estrutura do setor responsável pela elaboração do planejamento & Média & Desvio Padrão \\
\hline $\begin{array}{l}\text { Formação do servidor responsável pela função de P\&O } \\
\text { (0-Outros, 1-Contador) }\end{array}$ & 0,83 & 0,377 \\
$\begin{array}{l}\text { Setor responsável pela função de P\&O } \\
\text { (0-Setor de Planejamento, 1- Secretaria de Administração ou Finanças) }\end{array}$ & 0,91 & 0,291 \\
Total de tempo (em média) aplicado em funções de P\&O (meses) & 1,48 \\
Tamanho da equipe na função de P\&O (servidores) & 2,58 & 2,537 \\
Qualificação da equipe na função de P\&O (servidores) & 2,03 & 1,899 \\
\hline $\begin{array}{l}\text { Grau de Centralização na elaboração do planejamento } \\
\text { Participação dos setores na elaboração do planejamento (1- Departamentos não } \\
\text { participam do P\&O; 2- Eles validam o planejamento sugerido por Finanças, 3- Há } \\
\text { negociação do planejamento com Finanças; 4- Todos participam ativamente no processo } \\
\text { de P\&O) }\end{array}$ & 2 & Dédia \\
$\begin{array}{l}\text { Subordinação da administração indireta do governo local (1- Definição do planejamento } \\
\text { por Finanças; 2-As unidades poropõem seu orçamento próprio, sob certas restrições } \\
\text { impostas por Finanças; 3- As unidades elaboram seu próprio orçamento) }\end{array}$ & 1 & 1,022 \\
* P \& O - Planejamento e Orçamento - inclui atividades ex-ante: estimação das receitas e despesas, preparação do projeto de \\
$\begin{array}{l}\text { lei a ser submetido, e atividades ex-post: ajustes do plano de acordo com as iniciativas. } \\
\text { Fonte: Dados da pesquisa }\end{array}$
\end{tabular}

A Tabela 8 mostra que o processo do planejamento está sob a responsabilidade do contador e está alocado na Secretaria de Finanças, sem possuir um setor específico para isso. O ponto principal não é especificamente a formação do profissional que o elabora, e sim, a dedicação exclusiva a essa atividade. Nesse cenário, o orçamento é elaborado por demanda, e não conta com um processo de avaliação continua. O contador em determinados dias compartilha o tempo das atividades de natureza contábil ao processo de elaboração orçamentária. Tal dedicação parcial dificulta a condução do processo de forma a evolver outras secretarias e fazer do orçamento algo mais amplo. Pode favorecer também processos de estimação baseados em período anteriores.

$\mathrm{Na}$ média, os respondentes declararam investir um mês e meio por ano em atividades relacionadas ao planejamento, o que parece pouco se considerar-se que a atividade de planejamento requer não apenas a elaboração dos instrumentos iniciais (PPA, LDO e LOA), mas também seu acompanhamento. Por fim, a equipe média envolvida é de 2 a 3 (2.58) servidores, sendo que 2 deles são qualificados para a função (2.03).

O processo de elaboração do orçamento é centralizado na Secretaria de Finanças (0.91), validado em geral pelos departamentos, mas pouco discutido com a administração indireta. São elaborados pelos técnicos, com pouco envolvimento político no processo, seja pelo fato dos gestores comissionados não verem importância no planejamento público como ferramenta de gestão, ou por não considerarem como restritivo à barganha política pelos recursos entre secretarias. Com isso, há uma transferência das escolhas orçamentárias para os técnicos, sugerindo o que Rezende e Cunha (2013, p.272) chamam de déficit de democracia, dado que técnicos não tem suas decisões responsabilizadas por meio da eleição.

Em relação ao papel do controle legislativo e popular no processo, verificou-se que os municípios pouco promovem audiências públicas como demandado (LRF, art. 48, Estatuto das Cidades, art. 44). Quando as audiências ocorrem, a adesão da sociedade é baixa (4.49 cidadãos por sessão), seja pelo não oferecimento do orçamento participativo (0.08), pelo baixo número de audiências realizadas (2.0). Isso sugere que esses instrumentos de participação ainda cumprem apenas um caráter simbólico e cerimonial na maioria dos municípios (SANDER; PEDRALLI, 2013). A participação do próprio Legislativo no processo de planejamento também tem sido baixa, com pouca presença dos vereadores nas audiências (0.18). O resultado é coerente com a percepção dos respondentes sobre a importância dada pelos vereadores às audiências (5), que é muito baixa (Tabela 9). 
Tabela 9. Participação popular e Legislativa no processo de planejamento

\begin{tabular}{lcc}
\hline Participação popular & Média & $\begin{array}{c}\text { Desvio } \\
\text { Padrão }\end{array}$ \\
\hline $\begin{array}{l}\text { Audiências públicas na fase de elaboração do orçamento (1-não cumpre a lei; 2 atende os } \\
\text { requisitos legais mínimos, 3 - vai além das exigências legais) }\end{array}$ & 2,0 & 1,026 \\
$\begin{array}{l}\text { Uso de técnicas de orçamento participativo (0-não adota; 1-adota) } \\
\text { Participantes da sociedade nas audiências públicas de planejamento (número médio de } \\
\text { participantes) }\end{array}$ & $0,08,49$ & 0,268 \\
\hline Engajamento Legislativo & 7,272 \\
\hline $\begin{array}{l}\text { Participação dos vereadores nas audiências públicas (média) } \\
\begin{array}{l}\text { Emendas apresentadas pelos vereadores nos projetos de planejamento (0-não apresentam; } \\
1-\text { apresentam) }\end{array}\end{array}$ & 0,14 & $0,18,217$ \\
$\begin{array}{l}\text { Os vereadores (em minha cidade) não consideram importante participar das audiências } \\
\text { públicas do planejamento (1-discordo totalmente; } 3 \text { - indiferente, 5-concordo plenamente) }\end{array}$ & 5 & 1,237 \\
\hline
\end{tabular}
Fonte: Dados da pesquisa

Em relação ao baixo número de emendas apresentadas $(0,14)$, deve-se destacar que a possibilidade de veto das emendas pelo executivo pode acabar inibindo futuras contribuições dos vereadores na proposição de emendas à LOA. Contudo, os vereadores teriam maior possibilidade de exercer o controle e contribuir com o orçamento-programa se: (i) limitassem o espaço para alterações no orçamento na fase de execução, levando o executivo a aprimorar o planejamento, (ii) aumentassem a atenção às metas fiscais propostas na LDO, (iii) dessem força ao parecer do Tribunal de Contas na prestação anual de contas.

A Tabela 10 mostra os elevados limites de autorização para abertura de créditos adicionais dados ao Executivo. Apesar de se observar uma redução de 2000 a 2012 em 459 municípios, em 154 ainda se observam aumento nos limites aprovados.

Tabela 10. Percentual de mudanças no orçamento previsto autorizada pelo Legislativo em municípios do Estado de São Paulo

\begin{tabular}{|c|c|c|c|c|c|c|c|c|c|}
\hline \multirow{3}{*}{$\begin{array}{l}\text { Porte (milhares de } \\
\text { habitantes) } \\
<50\end{array}$} & \multirow{3}{*}{$\begin{array}{c}\mathbf{N} \\
(520)\end{array}$} & \multicolumn{4}{|c|}{$\begin{array}{l}\text { Municípios que aumentaram seus } \\
\text { próprios limites }\end{array}$} & \multicolumn{4}{|c|}{$\begin{array}{l}\text { Municípios que reduziram seus } \\
\text { próprios limites }\end{array}$} \\
\hline & & \multicolumn{2}{|c|}{$\begin{array}{l}\text { Limites em } \\
2000\end{array}$} & \multicolumn{2}{|c|}{$\begin{array}{l}\text { Aumento de } \\
2000 \text { a } 2012\end{array}$} & \multicolumn{2}{|c|}{ Limites em 2000} & \multicolumn{2}{|c|}{$\begin{array}{l}\text { Redução de } \\
2000 \text { a } 2012\end{array}$} \\
\hline & & 5.25 & (129) & 13.92 & (127) & 47.34 & $(312)$ & -28.93 & (363) \\
\hline 50 to 100 & $(50)$ & 8.67 & (12) & 14.25 & (12) & 40.62 & (29) & -18.05 & (38) \\
\hline 100 to 300 & (54) & 13.89 & (9) & 24.44 & (9) & 49.90 & $(31)$ & -24.30 & (44) \\
\hline$>300$ & (20) & 12.50 & (6) & 9.93 & (6) & 30.42 & (12) & -12.26 & (14) \\
\hline Total & $(644)$ & & (156) & & (154) & & (384) & & (459) \\
\hline
\end{tabular}

Nota: Número de municípios entre parênteses.

Fonte: Dados da pesquisa

A Tabela 11 mostra que a auditoria do TCE-SP não tem focado no planejamento. Os três principais motivos de reprovações são fiscais, e são observados pelo volume de recursos aplicados em relação ao limite legal ou fiscal. A eficiência ou cumprimento de metas físicas, ou a falha/ausência de estruturação de programas não tem sido motivo de reprovação. 
Tabela 11. Motivos de reprovação de contas e apontamentos pelo TCE-SP

\begin{tabular}{lccccccccc}
\hline Ano & $\mathbf{2 0 0 1}$ & $\mathbf{2 0 0 2}$ & $\mathbf{2 0 0 3}$ & $\mathbf{2 0 0 4}$ & $\mathbf{2 0 0 5}$ & $\mathbf{2 0 0 6}$ & $\mathbf{2 0 0 7}$ & $\mathbf{2 0 0 8}$ & $\mathbf{2 0 0 9}$ \\
\hline $\begin{array}{l}\text { Municípios com pareceres } \\
\text { desfavoráveis (\%) }\end{array}$ & 12.11 & 18.32 & 32.61 & 48.14 & 27.80 & 33.70 & 39.75 & 33.85 & 11.96 \\
\hline \multicolumn{7}{c}{ Motivos mais recorrentes de reprovação de contas: } & & & \\
\hline $\begin{array}{l}\text { Limites constitucionais (saúde, } \\
\text { educação) }\end{array}$ & 44.06 & 33.64 & 18.09 & 24.31 & 22.00 & 23.33 & 34.89 & 31.61 & 42.96 \\
$\begin{array}{l}\text { Regras fiscais (endividamento, } \\
\text { pessoal) }\end{array}$ & 26.57 & 21.82 & 40.70 & 39.01 & 15.43 & 13.90 & 13.06 & 25.32 & 25.19 \\
$\begin{array}{l}\text { Falta de pagamento de } \\
\text { Previdência }\end{array}$ & 12.59 & 14.09 & 13.39 & 14.15 & 30.57 & 37.47 & 31.72 & 19.41 & 5.19 \\
Outras irregularidades & 16.78 & 30.45 & 27.83 & 22.53 & 32.00 & 25.31 & 20.34 & 23.66 & 26.67 \\
\hline
\end{tabular}

Fonte: Tribunal de Contas do Estado de São Paulo

Porém, em períodos mais recentes já é possível notar uma mudança no comportamento dos Tribunais, quando contas começam a ser rejeitadas devido a problemas apurados com o planejamento, como o uso de indicadores e metas físicas genéricas, e alta imprecisão da estimação ${ }^{4}$. Ainda, iniciativas de índices para monitoramento da gestão, como o Índice de Efetividade da Gestão Municipal (IEGM/TCESP), também podem vir a gerar melhorias na adoção de melhores práticas nos municípios.

\section{CONSIDERAÇÕES FINAIS}

A entrada do orçamento-programa em 2002 trouxe uma estrutura mínima de programas e indicadores. Contudo, a dinâmica orçamentária vigente, nos municípios analisados, ainda segue o modelo de input-based budget com pouca ou nenhuma avaliação da eficiência dos programas, e com baixa utilização das metas físicas e indicadores desenvolvidos no orçamento. Portanto, tais municípios demonstram possuir baixa capacidade de assimilação das reformas recentes que o Brasil propôs em seu ciclo PFM.

Os resultados mostram que nos municípios analisados a falta de setores específicos dedicados à função do planejamento em geral coloca esta função sob a responsabilidade do contador, lotado na Secretaria de Finanças. O planejamento é desenvolvido quase sempre de forma centralizada, com pouca participação das demais secretarias e órgãos da Administração Indireta. A estimação de receitas e despesas é baseada em métodos, perpetuando assim a alocação anterior de recursos entre as diversas secretarias.

Observou-se ainda um baixo envolvimento do legislativo local na elaboração e aprovação do orçamento, visto a baixa apresentação de emendas aos instrumentos de planejamento, a ausência dos vereadores nas audiências públicas, além de uma baixa participação popular no processo.

Quanto ao controle externo, eventuais deficiências no orçamento não têm sido alvo recorrente de reprovação de contas, o que incentiva a baixa maturidade do processo. Ressalta-se, porém, o projeto AUDESP do TCE-SP que ampliou a informatização do acompanhamento do planejamento dos municípios, e o surgimento de reprovação de contas por questões relacionadas ao planejamento, o que pode demonstrar mudanças no comportamento do controle externo.

Como uma das principais fontes de coerção à adoção da regulação viria do controle externo (POWER, 1997), sugere-se para pesquisas futuras investigar tal fonte de coerção comparando municípios de mesmo porte de estados cujo Tribunal de Contas tenha um nível de informatização do processo de coleta de dados diferente do adotado pelo TCE-SP desde 2009.

Mesmo com a modesta difusão das reformas, há que se mencionar que são notados avanços no planejamento, visto que os municípios de pequeno porte já adotam medidas de desempenho, mesmo que em fase embrionária. A continuidade da implantação do orçamento-programa e efetivo uso da informação para avaliação dos programas será vista nos próximos anos, que pode vir a ser intensificada e fortalecida pela atuação dos Tribunais de Contas e dos Controles Internos. 


\section{REFERÊNCIAS}

ALLEN, R. The Challenge of Reforming Budgetary Institutions in Developing Countries: IMF Working Paper. Washington D.C.: IMF, 2009.

ANDREWS, M. The Limits of Institutional Reform in Development. New York: Cambridge University Press, 2013.

AQUINO, A. C. B. DE; AZEVEDO, R. R. DE; LINO, A. F. Isomorfismo, Tribunais de Contas e a automatização da coleta de dados de municípios. Congresso USP de Controladoria e Contabilidade. Anais...São Paulo: 2016

ARANTES, R. B.; ABRUCIO, F. L.; TEIXEIRA, M. A. C. A imagem dos tribunais de contas subnacionais. Revista do Serviço Público, v. 56, n. 1, p. 57-85, 2005.

BISSESSAR, A. M. An institutional review of planning budgeting and monitoring in the Caribbean. International Journal of Public Sector Management, v. 23, n. 1, p. 22-37, 26 jan. 2010.

FLYNN, N. The future of public sector management: Are there some lessons from Europe? International Journal of Public Sector Management, v. 8, n. 4, p. 59-67, 1995.

GIACOMONI, J. Bases normativas do plano plurianual: análise das limitações decorrentes da ausência de lei complementar. Revista de Administração Pública, v. 38, n. 1, p. 79-91, 2004.

GUESS, G. M.; LELOUP, L. T. Comparative Public Budgeting. New York: Suny Press, 2010.

IBGE. Pesquisa de Informações Básicas Municipais (1999). In: Perfil dos Municípios Brasileiros. Brasília, DF: IBGE, 1999.

JOYCE, P. Introduction to Symposium: The Crisis in Federal Budgeting. Public Budgeting \& Finance, v. 32, n. 3, p. 1-3, 2012 .

LOPES, C. T. G. Planejamento Estado e crescimento. São Paulo: Pioneira, 1990.

LOUREIRO, M. R.; TEIXEIRA, M.A. C.; MORAES, T. C. Democratização e reforma do Estado: o desenvolvimento institucional dos tribunais de contas no Brasil recente. Revista de Administração Pública, v. 43, n. 4, p. 739-772, 2009.

MACHADO JR., J. T. A experiência brasileira em orçamento-programa - uma primeira visão. Revista de Administração Pública, v. 46, n. 4, p. 1157-1175, 2012.

MCGILL, R. Performance budgeting. International Journal of Public Sector Management, v. 14, n. 5, p. 1-29, 2001.

MELLO, D. L. DE. Governo e administração municipal: a experiência brasileira. Revista de Administração Pública, v. 35, n. 2, p. 79-96, 2001.

MOON, M. J.; DELEON, P. Municipal Reinvention: Managerial Values and Diffusion among Municipalities. Journal of Public Administration Research and Theory, v. 11, n. 3, p. 327-351, 2000.

POLlitT, C.; BOUCKAERT, G. Public Management Reform. 3th. ed. New York: Oxford Press, 2011.

POWER, M. The Audit Society: Rituals of Verification. Oxford: Oxford Un. Press, 1997.

REZENDE, F.; CUNHA, A. A reforma esquecida. Orçamento, gestão pública e desenvolvimento. Rio de Janeiro: Ed. FGV, 2013.

ROCQUE, G. DE LA. Contabilidade Pública. Rio de Janeiro: Editora Fundo de Cultura, 1963.

SANDER, J. A.; PEDRALLI, J. R. As audiências públicas enquanto práticas cerimoniais. Como torna-las de fato públicas? $1^{\circ}$ Seminário Nacional de Planejamento e Desenvolvimento. Anais...Curitiba/PR: 2013

SCHICK, A. Incremental Budgeting in a Decremental Age. Policy Sciences, v. 16, p. 1-25, 1983.

SCOTT, R. W. Institutions and Organizations. Ideas, Interests, and Identities. 4th ed. ed. Thousand Oaks, CA: SAGE Publications, 2014.

TOLLINI, H. Reforming the Budget Formulation Process in the Brazilian Congress. OECD Journal on Budgeting, v. 2009, p. 1-29, 2009. 
${ }^{1}$ No final da década de 90, a NPM levou à adoção de contratualização por desempenho e gestão por projetos em pontos isolados da administração federal e estadual no Brasil. Tais iniciativas responsabilizam secretarias, autarquias, e demais organizações públicas por resultados (ex. metas físicas de volume de serviço, satisfação no atendimento, custo do serviço). Resultados associados ao orçamento previsto, seja no planejamento, na liberação de recursos ou na avaliação de desempenho, são vistos como variações do modelo MBO. Contudo tais iniciativas são exceções, pois a regulação de orçamento público no Brasil (Lei 4.320, Constituição de 1988, EC 19/98, LRF, e Portaria MOPG 42/99), não obriga o uso de acordos de resultados ou responsabilização de gestores.

${ }^{2} \mathrm{O}$ governo federal possui considerável estrutura de apoio na sua tarefa de aprovação, acompanhamento e fiscalização do orçamento. O legislativo nacional possui consultores (conselheiros) altamente qualificados em matéria orçamentária: 40 consultores na Assessoria do Orçamento da Câmara dos Deputados e 25 na Assessoria do Orçamento do Senado (TOLLINI, 2009).

${ }^{3}$ Foram eliminadas as respostas duplicadas para o mesmo município; as incompletas, e as de gestores de outras áreas diferentes do planejamento.

${ }^{4}$ Processo TC 001286/126/11: http://www4.tce.sp.gov.br/sites/default/files/065-m-amfs-tc-001286-026-11.pdf 